\title{
Erratum to: Inhibition of mixed-layer deepening during winter in the northeastern Arabian Sea by the West India Coastal Current
}

D. Shankar ${ }^{1,2}\left(\right.$ D $\cdot$ R. Remya $^{1,2} \cdot$ P. N. Vinayachandran ${ }^{3} \cdot$ Abhisek Chatterjee $^{4}$. Ambica Behera ${ }^{3}$

Published online: 10 August 2016

(C) Springer-Verlag Berlin Heidelberg 2016

\section{Erratum to: Clim Dyn}

DOI 10.1007/s00382-015-2888-3

In the above-mentioned article, Fig. 4 was published incorrectly. The correct version of Fig. 4 is given below.

The online version of the original article can be found under doi:10.1007/s00382-015-2888-3.

D. Shankar

shankar@nio.org

1 CSIR-National Institute of Oceanography, Dona Paula, Goa 403004, India

2 Academy of Scientific and Innovative Research (AcSIR), CSIR-National Institute of Oceanography, Dona Paula, Goa, India

3 Indian Institute of Science, Bangalore, India

4 ESSO-Indian National Centre for Ocean Information Services, Hyderabad, India 
Fig. 4 Climatological monthly latent heat flux (top left), sensible heat flux (top right), net longwave flux (middle left), net shortwave flux (middle right), and net heat flux (bottom left) during January in the NEAS. Superimposed on these five maps are the MLD contours (metres) for January; the MLD for January is plotted in the bottom right panel. All the fluxes are in $\mathrm{W} \mathrm{m} \mathrm{m}^{-2}$, with positive values implying a flux out of the ocean; note that the colour scale is different for each panel. The flux climatologies were computed using data for 1979-2013. Superimposed on the flux and MLD maps are the wind stress vectors (dyne $\mathrm{cm}^{-2}$ ). The wind stress and fluxes are from Praveenkumar et al. (2012), and the MLD is based on Chatterjee et al. (2012). The 200- and $1000-\mathrm{m}$ isobaths are marked
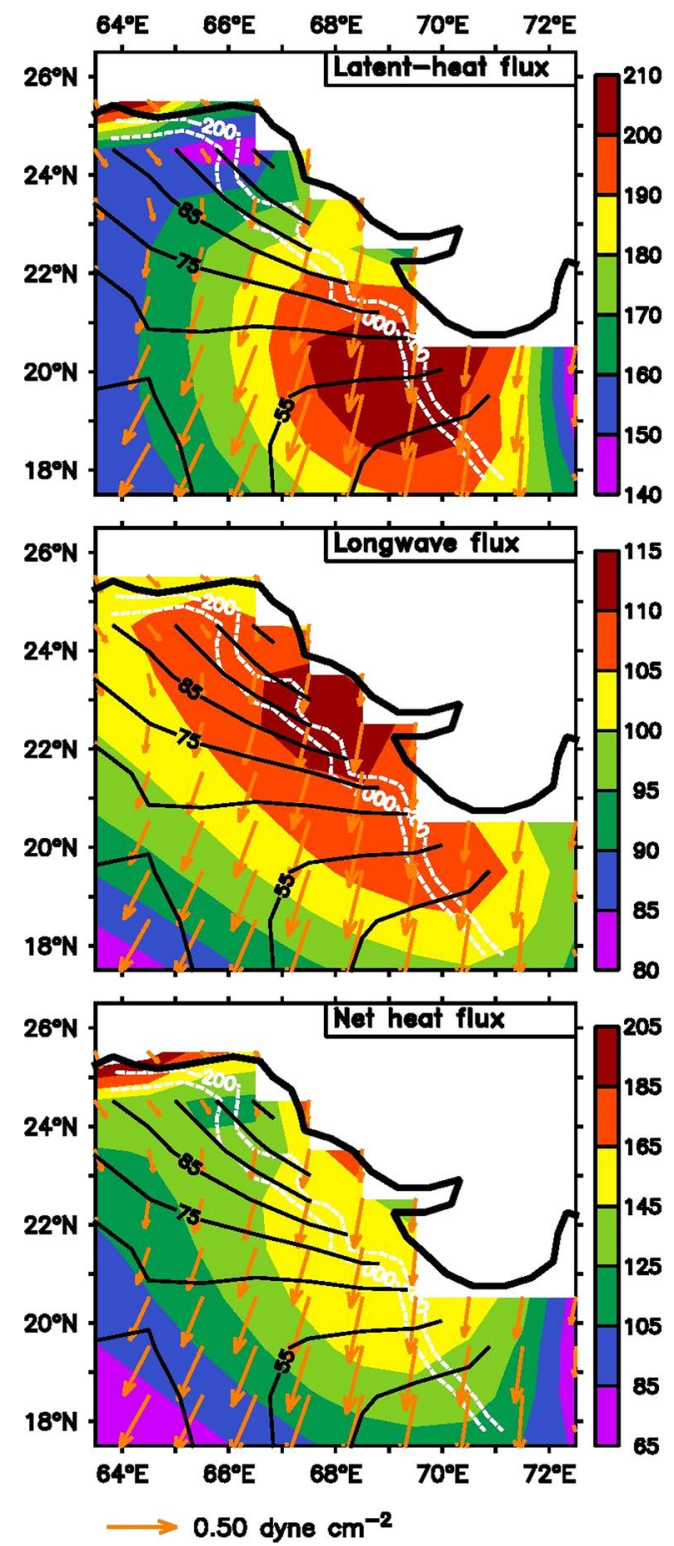
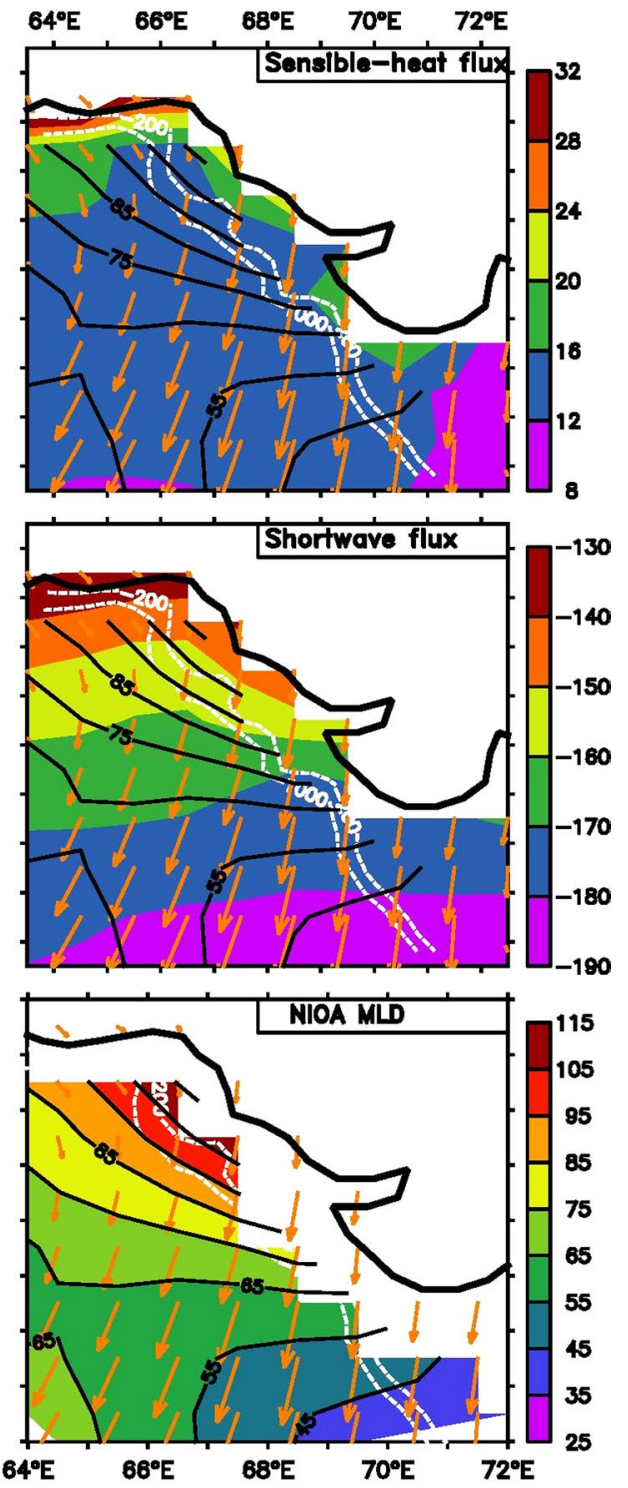